\title{
Overview of Altair's Thermal Control System and the Associated Technology Development Efforts
}

\author{
Ryan A. Stephan \\ NASA Johnson Space Center \\ 2101 NASA Road One \\ Houston, Texas 77058 \\ 281-483-7182 \\ Ryan.A.Stephan@nasa.gov
}

\begin{abstract}
In early 2004, President Bush announced a bold vision for space exploration. One of the goals included in this vision is a return to the moon by 2020 . In response to this vision, NASA established the Constellation Program, which includes several project offices.
\end{abstract}

One of the Constellation projects is Altair, which is the next generation Lunar Lander. The future Altair missions are very different than the Lunar missions accomplished during the Apollo era. As such, there are several project risks and design challenges that have never before been addressed. Due to the unique thermal environment associated with this mission, many of these risks and design challenges are associated with the vehicle's thermal control system. NASA's Exploration Systems Mission Directorate (ESMD) includes the Exploration Technology Development Program (ETDP). ETDP consists of several technology development projects. The project chartered with mitigating the aforementioned risks and design challenges is the Thermal Control System Development for Exploration Project.

The current paper will summarize the Altair mission profile, the operational phases, and the thermal design challenges unique to this particular vehicle. The paper will also describe the technology development efforts being performed to mitigate the risks and design challenges. The technology development project is performing a rigorous development effort that includes thermal control system fluids, evaporators, heat exchangers, and Lunar surface radiators.

\section{TABLE OF CONTENTS}

1. INTRODUCTION.

2. AltAIR OVERVIEW . .1

3. ALTAIR THERMAL CONTROL SYSTEM OVERVIEW............2 4. ALTAIR THERMAL TECHNOLOGY DEVELOPMENT EFFORTS

5. CONCLUSION

6. ACKNOWLEDGEMENTS

7. REFERENCES.

\section{INTRODUCTION}

In response to the president's 2004 vision for space exploration, NASA is planning a human return to the moon prior to 2020. In preparation for this mission, NASA has established the Constellation Program. Within the
Constellation Program, there are several project offices. One of these projects includes the development of NASA's new lunar lander vehicle. The overall mission architecture for this vehicle, Altair, is very similar to Apollo's architecture.

This paper will provide the reader with an overview of the Altair vehicle. In addition, Altair's thermal control system, including the functionality and the hardware, will be discussed. The paper will also describe the technology development process and the various technology developments currently underway.

\section{Altair OVERVieW}

The current lunar mission architecture requires the use of two separate launch vehicles (Ares I and Ares V). In addition to these assets, a successful mission also requires an Earth Departure Stage (EDS), an Orion crewed vehicle, and the aforementioned Lunar lander. The larger of the two launch vehicles, Ares V, first lifts the EDS and the Altair into Low Earth Orbit (LEO). Shortly thereafter, the second launch vehicle, Ares I, launches Orion into LEO with four crewmembers on the vehicle. Orion and the Altair/EDS stack rendezvous in LEO and the EDS propels the now integrated stack on a trajectory to the moon. The EDS is then jettisoned after the translunar injection burn. The translunar cruise takes approximately three days to complete. After the vehicles are at the moon, Altair is used to insert the vehicles into a $100 \mathrm{~km}$, circular Low Lunar Orbit (LLO). The vehicles spend approximately 24 hours in LLO before Altair separates from Orion and begins its descent to the Lunar surface. The entire descent phase takes approximately four hours to complete. Once on the surface, the Lunar surface phase is started and lasts for seven days. Throughout this time, the crew will perform up to seven extravehicular activities. Each EVA includes two crewmembers for eight hours. In total, approximately 112 man-hours will be spent outside of the pressurized cabin. Once the seven days have elapsed, the ascent module carries the four crewmembers back to the awaiting Orion capsule where the vehicles rendezvous in LLO. Once aboard Orion, the Altair ascent module is jettisoned back to the Lunar surface and Orion's service module pushes the crew back to Earth where the Orion crew module lands safely in the ocean $^{1}$. 
Altair consists of three functional components as shown in Figure 1.

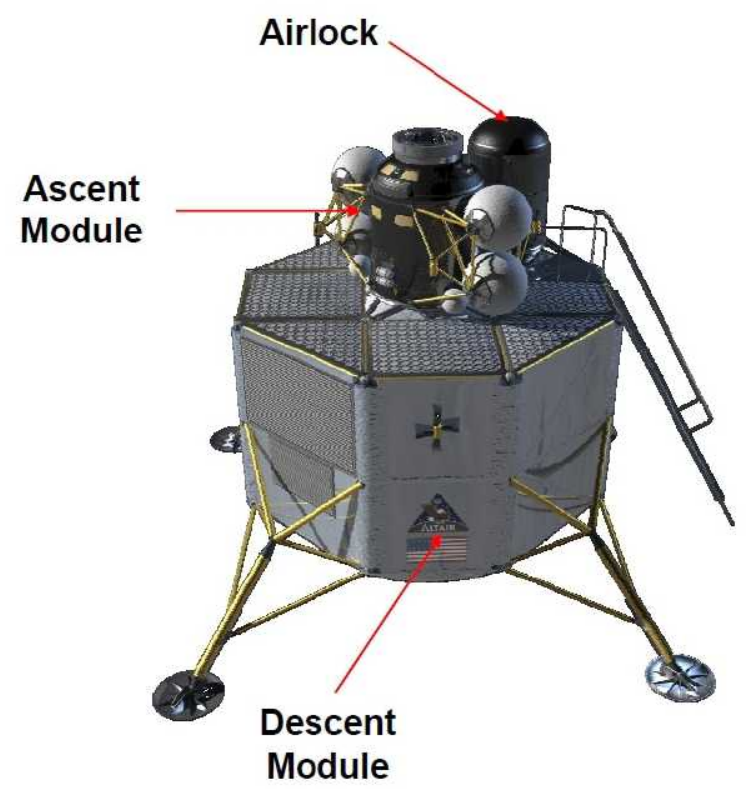

Figure 1. Altair Lunar Lander showing three functional components (Airlock, Ascent Module, and Descent Module).

The largest and most massive component is the Descent Module (DM). The DM is an unpressurized module and consists of composite struts and includes the main propulsion system required to perform the Lunar orbit insertion burn, lunar descent, and landing on the lunar surface. The main propulsion system is composed of eight massive propulsion tanks. Of these tanks, four of them contain liquid hydrogen while the remaining four tanks are filled with liquid oxygen. The propellant within these tanks is required to fuel the engine. The two smaller structures are referred to as the Ascent Module (AM) and the AirLock (AL). As indicated by the name, the AM is used to return the crew to Orion after the Lunar surface stay. The four crewmembers, the overwhelming majority of the avionics, and a small ascent engine are included in the AM design. The AM is nominally pressurized to 10.2 psia while docked with Orion and 8.3 psia while on the lunar surface. The AL is attached to the AM through a docking tunnel and is maintained at the same pressure as the AM throughout the mission. The $\mathrm{AL}$ is used to ingress and egress the vehicle during extravehicular activities. This implies that the $\mathrm{AL}$ is depressurized and repressurized several times.

As mentioned above, Altair is designed to take a crew of four to the Lunar surface and support operations for up to seven days. These mission requirements far exceed the Apollo capability of two crewmembers for a total of three days on the Lunar surface. In addition to these differences, another major difference is that Altair is required to perform the Lunar orbit insertion burn. On Apollo, the command/service module was tasked with performing the Lunar orbit insertion burn. However, because Orion had to be optimized for earlier LEO missions, the Lunar orbit insertion burn will be performed by Altair, which resulted in a much heavier vehicle.

\section{ALTAIR THERMAL CONTROL SYSTEM OVERVIEW}

Some degree of thermal control is required for all types of spacecraft from the simplest satellites to the most complex manned space vehicles. In its most basic form, thermal control is the maintenance of all vehicle surfaces and components within an appropriate temperature range. For satellites, this requires that the thermal control system must maintain all of the equipment within its operating temperature range. Similar to satellites, the thermal control system for manned space vehicles must also maintain all of the equipment within its operating temperature. In addition to component level temperature maintenance, the manned spacecraft thermal control system must also safely maintain the internal cabin temperature within the appropriate temperature requirements for crew comfort. 
An effective thermal control system must provide three basic functions. The three functions are heat acquisition, heat transport, and heat rejection. Heat acquisition is the process of transferring thermal energy from the heat source to the thermal control system. On the Altair Lander, heat acquisition is accomplished using various coldplates and heat exchangers as shown in Figure 2. Figure 2 is the current thermal control system schematic.
There are a total of 33 coldplates included in the Altair thermal control system. The overwhelming majority of these coldplates are located on the vehicle's ascent module. The coldplates are required to acquire excess thermal energy from various avionics components and maintain these devices within their acceptable temperature limits. The heat-generating components include computers, inertial measurement units, monitors, etc. There are two types of heat exchangers included in the system design. The first

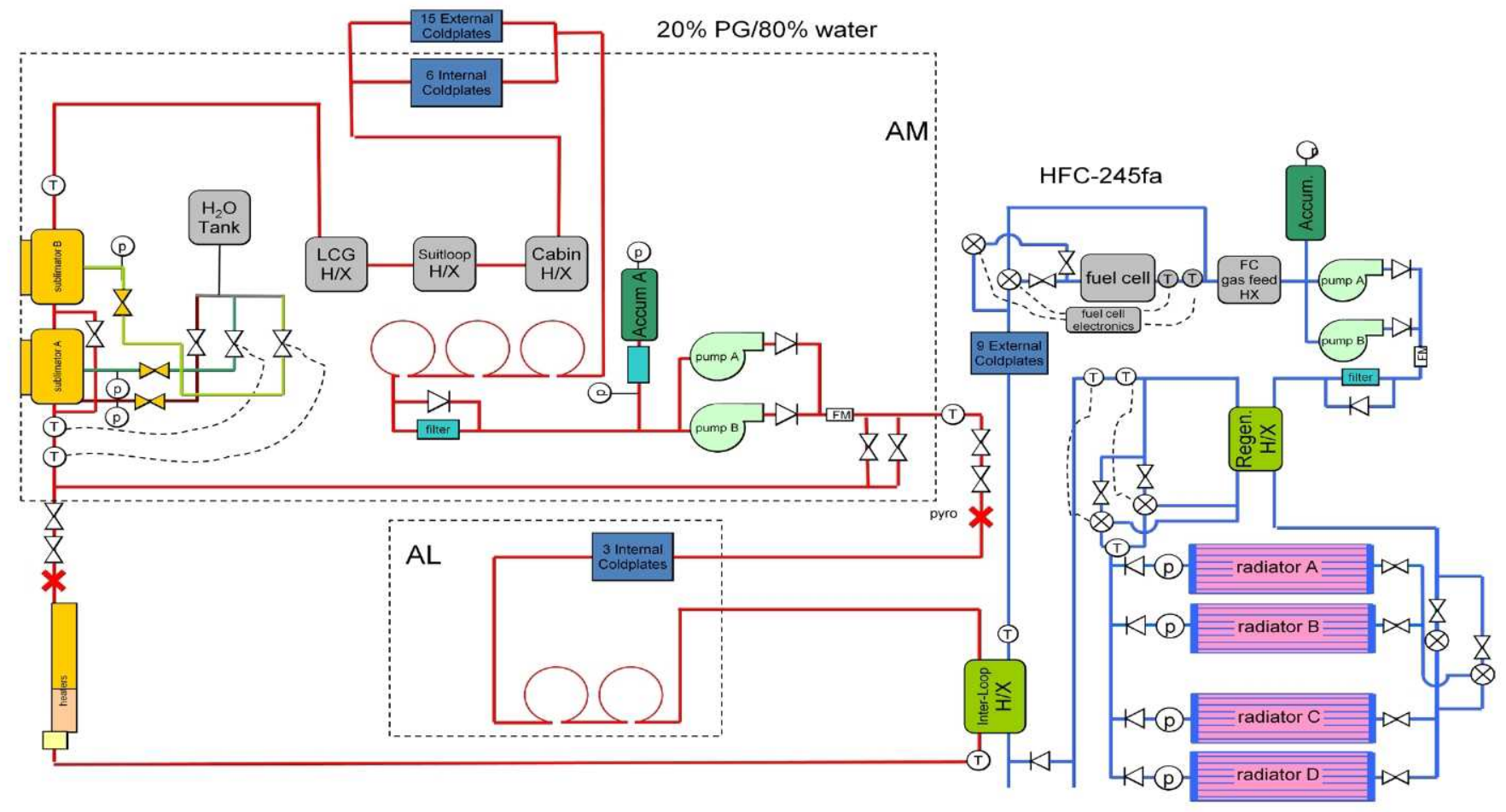

Figure 2. Altair Lander thermal control system schematic. 
heat exchanger type is an air/liquid heat exchanger and acquires energy from an air loop and transfers it to the liquid thermal control loop. There are two air/liquid heat exchangers included in the thermal control system design. The second type of heat exchanger is a liquid/liquid heat exchanger and it acquires energy from one liquid loop and transfers it to a second liquid loop. There are a total of three liquid/liquid type heat exchangers. The first is the Liquid Cooling Garment (LCG) heat exchanger and its purpose is to acquire energy from the crew's LCG and transfer it to the thermal control system. The second liquid/liquid heat exchanger is the interface heat exchanger. This heat exchanger is used to transfer energy from the internal pumped fluid loop to the external pumped fluid loop. The third, and final, liquid/liquid heat exchanger is the regenerative heat exchanger and it is used to maintain the system set point throughout the entire mission profile.

The second critical function of a thermal control system is heat transport. Heat transport, as implied by the name, is the movement of energy from one region to another. In the Altair thermal control system, this function is accomplished using two separate pumped fluid loops. The internal thermal control system pumped fluid loop, depicted as red in Figure 2. includes a mixture of propylene glycol and water as the working fluid. This loop gathers energy from the various heat exchangers and coldplates located in the ascent module and the airlock. This acquired energy is transferred to the external loop through the inter-loop heat exchanger. HFC-245fa is the baseline working fluid for the external thermal control system. HFC-245fa is a hydrofluoro-carbon and was developed as a replacement to the ozone-depleting chloroflurorcarbon. The acquired energy is then transported to the radiator where it is then rejected to space. Although not as mass efficient as a single loop architecture, the various mission phases resulted in a two loop thermal control system architecture. The thermal control system is exposed to an extremely cold environment during TransLunar Coast (TLC). Resultantly, it is desirable to use a fluid with a low freezing temperature so as not to freeze the fluid when the environment is cold. Unfortunately, the majority of fluids with a low enough freeze temperature to withstand the cold environments of TLC are also hazardous to the crew in the event of an inadvertent system leak. Therefore, the system is designed to use a non-toxic fluid in the pressurized modules and a more toxic fluid (with a low freeze temperature) in the external loop.

The third, and final, function of a thermal control system is heat rejection. Heat rejection is the process of rejecting the excess thermal energy acquired by the thermal control system to the external environment. The Altair thermal control system relies on two separate hardware components to achieve this function. The vehicle's heat rejection requirement varies throughout the Lunar mission as shown in Figure 3.

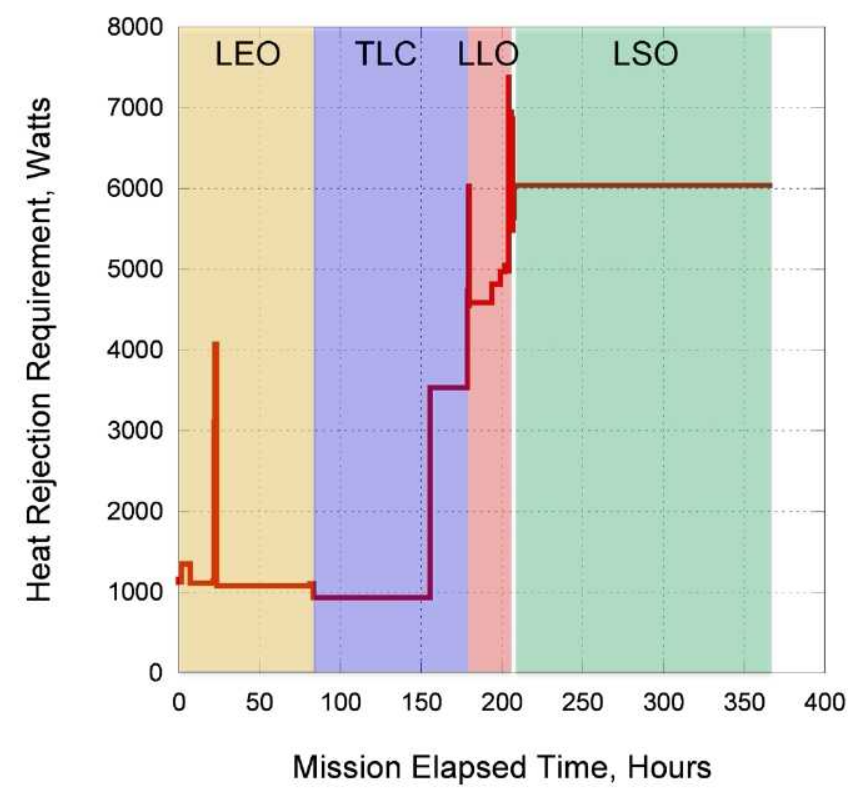

Figure 3. Altair heat rejection requirement throughout the Lunar Surface Operations (LSO) mission phase.

In the preceding figure, the heat rejection requirement is located along the abscissa and the elapsed mission time is shown along the ordinate. The plot is color-coded by the location in the mission profile. Starting from the left, the gold region represents the duration that the vehicle is located in Low Earth Orbit (LEO) while the purple region is TLC. During both of these mission phases, the radiators are used to reject the full vehicle heat load. The radiators are unable to reject the vehicle's heat load during Low Lunar Orbit due to the relatively warm environmental temperature. A more complete description of this thermal environment will be provided later in this document. When the radiators are unable to reject the full vehicle heat load, the sublimator is used as a Supplemental Heat Rejection Device (SHReD). During descent to the Lunar surface (not colored in Figure $3)$, the sublimator is the sole heat rejection device. The overwhelming majority of the mission is spent on the Lunar surface and is colored green in the preceding figure. Because it's the highest continuous heat rejection requirement, the thermal control system is designed for Lunar surface operations. The radiators are sized for this mission phase and are used as the only means of heat rejection during the Lunar Surface Operations (LSO). Just prior to ascent from the Lunar surface, the pyrotechnic valves shown in Figure 2 (indicated by the red x's) are actuated to separate the ascent module from the airlock and the descent module. During Lunar ascent, because the radiators are left behind, the sublimator is used as the heat rejection device. The sublimator is used throughout ascent, LLO rendezvous with Orion, and ascent module disposal. During these periods, the vehicle heat rejection requirement varies between 750 Watts and 3120 Watts. 


\section{Altair thermal TeChNOLOgY DEVELOPMENT EFFORTS}

The following section will be divided into several subelements, which are the various technology development efforts relevant to the Altair thermal control system.

THERMAL CONTROL SYSTEM (TCS) FLUIDS - The overwhelming majority of United States' manned space vehicles have used a pumped fluid loop as the primary means of heat transport during the mission. These fluids have ranged from an ethylene glycol/water mixture on Apollo to the Orbiter with water (internal loop) and Freon ${ }^{\circledR}$ (external loop). As mentioned above, the current baseline thermal control system design for Altair (as well Orion and the Lunar Habitat) also depends on a mechanically pumped fluid loop. A mixture of propylene glycol and water is the baseline internal working fluid for the aforementioned Constellation projects. This fluid has never before been used for a manned vehicle so there is little long duration data for this fluid in a flight-like thermal control system.

The technology development project worked with the Orion and Altair Active Thermal Control (ATCS) fluid working group to develop and fabricate a long duration fluids life test bed. The test bed was designed to include all of the materials inherent in a vehicle thermal control system. The primary objective of the test was to assess the long-term stability of the working fluid over a period of ten years. The working fluid for this test was a mixture of Dowfrost ${ }^{\mathrm{TM}} \mathrm{HD}$ and water. The planned ten year evaluation period corresponded to the expected lifetime of the Lunar Habitat's thermal control system. The fluid was scheduled to be withdrawn on a periodic basis and analyzed for corrosion byproducts and microbial growth. Additionally, provisions were made to remove material samples from the test cart for further analysis. A schematic of the test cart is shown in Figure 4.

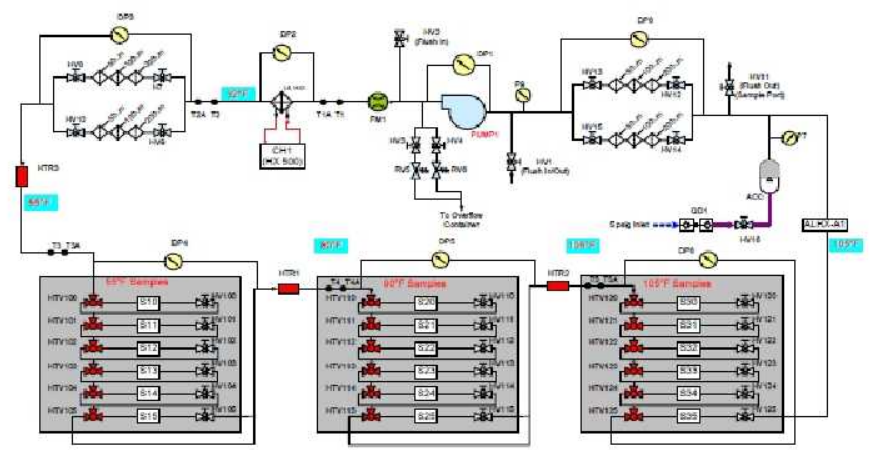

Figure 4. Test cart schematic for the technology development project's fluids life test.

Unfortunately, the test was stopped after only two months because the system filters became clogged with an unexpectedly high amount of precipitates. This high level of precipitation rendered the system inoperable. After completing the test, the precipitate was analyzed and the composition contained aluminum, which could have only come from the materials in the test stand. Additionally, the fluid $\mathrm{pH}$ had increased from 10.1 at the beginning of the test to 12.2 less than two months later. The technology development project is currently working with the Orion project to determine the cause of the fluid instability and to identify alternative working fluids. Because the test infrastructure is already in place, the technology development project will reconfigure the test cart and repeat last year's test with the most promising formulation of propylene glycol.

SUBLIMATOR DRIVEN COLDPLATE - The project has invented and started the development of an advanced technology concept that combines all three thermal control system functions into a single piece of hardware. This novel hardware component is called the Sublimator Driven Coldplate (SDC) and has the potential of replacing the entire thermal control system with one hardware component ${ }^{2}$. Another unique feature of this concept is that it does not use any power and includes no moving parts. The target application for the SDC is the Altair Ascent Module due to the low heat load, short transport distance, and short mission duration requirements for this vehicle. This technology would eliminate the need for a pumped fluid loop as all of the heat loads would be conductively coupled to a sublimator. Another promising use for this technology could be accomplished by integrating the SDC with a pumped fluid loop. By doing this, the SDC could be used as a traditional coldplate for the LSO phase of the mission. Because a sublimator requires a consumable feedwater, it cannot be mass-effectively used as the sole source of heat rejection during the Lunar surface stay. If integrated with a pumped fluid loop, the SDC could be used during ascent in place of the pumped fluid loop or could serve as a dissimilar source of redundancy.

In the past, the project has completed the design and analysis for two SDC engineering development units. In addition, the project executed performance tests for an SDC coupon design. One of the two SDC EDUs was chosen for fabrication and is shown in Figure 5. 


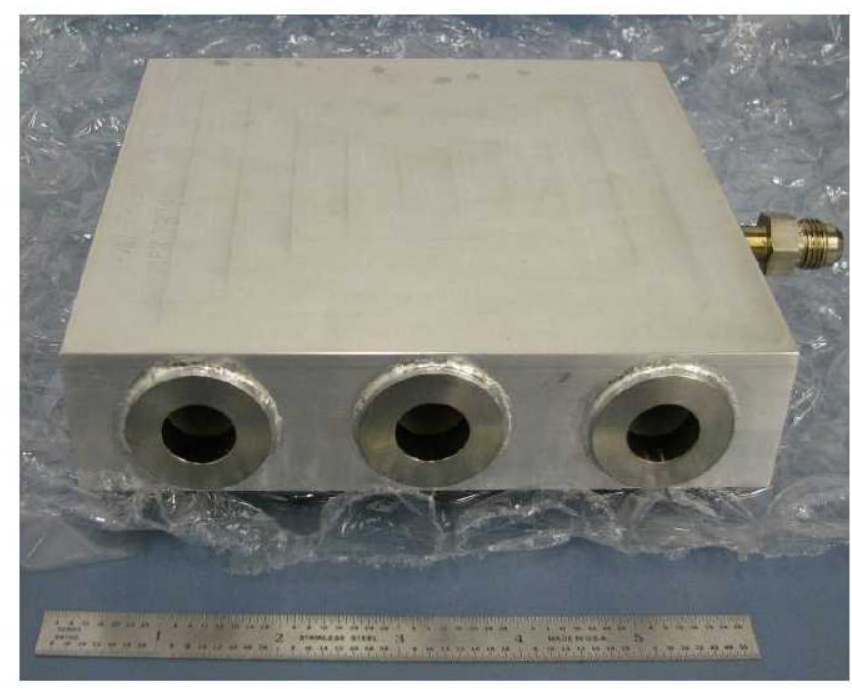

Figure 5. Sublimator Driven Coldplate Engineering Development Unit as delivered to JSC.

The preliminary designs for this particular SDC unit show a potential mass savings of approximately $25 \%$ if the SDC were used to replace the entire ascent module thermal control system. The EDU shown in Figure 5 was tested at JSC and was shown to meet all of its performance specifications.

COMPOSITE HEAT EXCHANGERS - As described above, there are several heat exchangers included in the Altair thermal control system design. The use of composites for these types of hardware is an attractive alternative to traditional metallic heat exchangers. Carbonbased composites have very high thermal conductivities making them more effective heat transfer devices. In addition, composites also have a high strength to mass ratio, which has the potential of reducing the hardware mass. The project has previously explored the benefit of using these advanced materials to fabricate radiators. However, heat exchanger construction is significantly different and requires a more detailed investigation.

The project is currently engaged in the development of a composite air/liquid heat exchanger EDU. The composite heat exchanger EDU was designed to transfer approximately $3.4 \mathrm{~kW}$. The fabricated EDU, which is shown in Figure 6, is approximately $37 \%$ lighter than the metallic baseline.

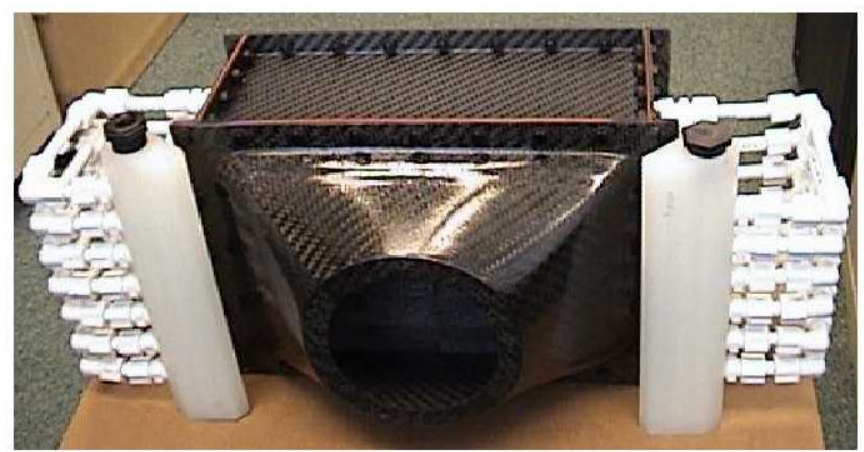

Figure 6. Technology development project's air/liquid composite heat exchanger engineering development unit.

In parallel with the air/liquid heat exchanger development, the project is also designing a liquid/liquid heat exchanger. The liquid/liquid heat exchanger design will be compared to the metallic baseline and another liquid/liquid heat exchanger technology discussed in an upcoming section. If this design shows potential for mass savings, the project will fabricate and test an engineering development unit.

MICROCHANNEL HEAT EXCHANGER - The technology development project has started a collaboration with Pacific Northwest National Laboratories (PNNL) to develop microchannel liquid/liquid heat exchangers. As shown in Figure 2, there are a total of three liquid/liquid heat exchangers included in the Altair thermal control system design.

The first step in the assessment of this technology was to establish a baseline for future comparison. To that end, a test cart was designed and used to assess the performance of a mass-optimized flight heat exchanger design for use on NASA's Crew Return Vehicle (X-38). This heat exchanger was designed to transfer energy from a warm de-ionized water loop to a cooler loop containing a mixture of ethylene glycol and water. The $2.7 \mathrm{~kg}$ heat exchanger was designed to transfer approximately $3.1 \mathrm{~kW}$ between the two loops. The X-38 heat exchanger performance specifications were supplied to PNNL as the requirements for a microchannel heat exchanger. PNNL designed, fabricated, and delivered a microchannel heat exchanger intended to meet those same performance specifications. The microchannel and baseline heat exchangers are shown in Figure 7. 


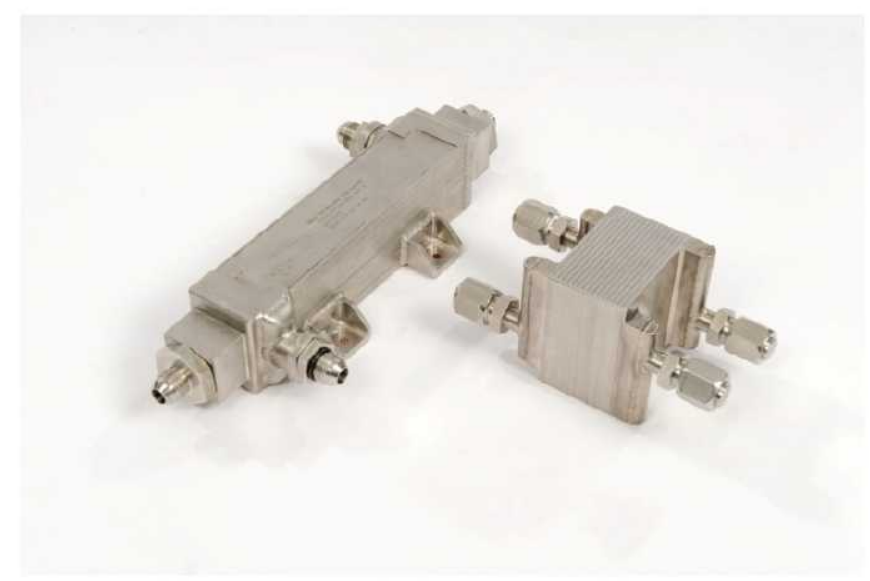

Figure 7. Baseline $\mathrm{X}-38$ liquid/liquid heat exchanger (left) and PNNL's microchannel heat exchanger (right).

It is apparent from Figure 7 that the microchannel heat exchanger is significantly smaller than the baseline unit. In fact, the volume of the microchannel heat exchanger is only $311 \mathrm{~cm}^{3}$ versus $2180 \mathrm{~cm}^{3}$ for the X-38 baseline. In addition, the mass savings associated with this unit is approximately $0.65 \mathrm{~kg}$ or $24 \%$. The microchannel heat exchanger has not yet been tested so the technology development project has not demonstrated that it meets its performance requirements.

EVAPORATIVE HEAT SINKS ${ }^{3}$ - Evaporative heat sinks are a type of heat exchanger that remove energy from the thermal control system by evaporating a fluid and venting the fluid vapor to the external environment. For short mission durations or mission phases, evaporators are much more mass efficient than radiators as heat rejection devices. As briefly discussed above, Altair will use an evaporative heat sink, specifically a sublimator, during LLO, descent, and ascent.

The Lunar orbital environment presents very unique challenges for the thermal control system. Figure 8 shows the spatial variation of the Lunar surface temperature.

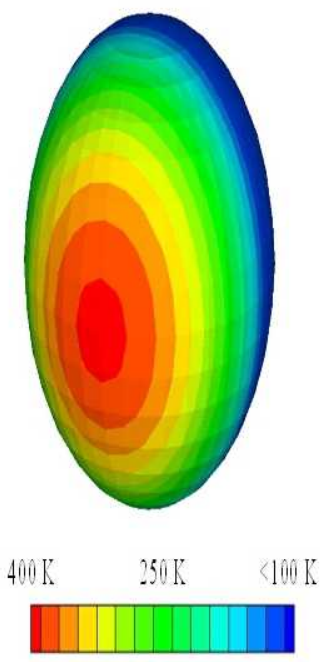

Figure 8. Spatial distribution of the Lunar surface temperature.

The hottest portion of the Lunar surface corresponds to the point directly aligned with the sun (subsolar point). In the preceding figure, the maximum surface temperature is approximately 400 Kelvin while the minimum temperature is less than 100 Kelvin on the dark side. The extreme surface variation results in a large swing in radiator sink temperatures while Altair is operating in low Lunar orbit. The large sink temperature variations are problematic because it is impractical (sometimes even impossible) to use a radiator as the sole means of heat rejection during LLO if the radiators have a large infrared incident load from the Lunar surface. The sink temperature corresponding to the location immediately above the subsolar point exceeds the setpoint temperature of the Altair thermal control system. As a result, the baseline Altair design includes a Supplemental Heat Rejection Device (SHReD) as previously described. Figure 9 represents the variability of Altair's heat rejection capability using only radiators for a beta angle of zero degrees, which is the worst case hot LLO environment. 


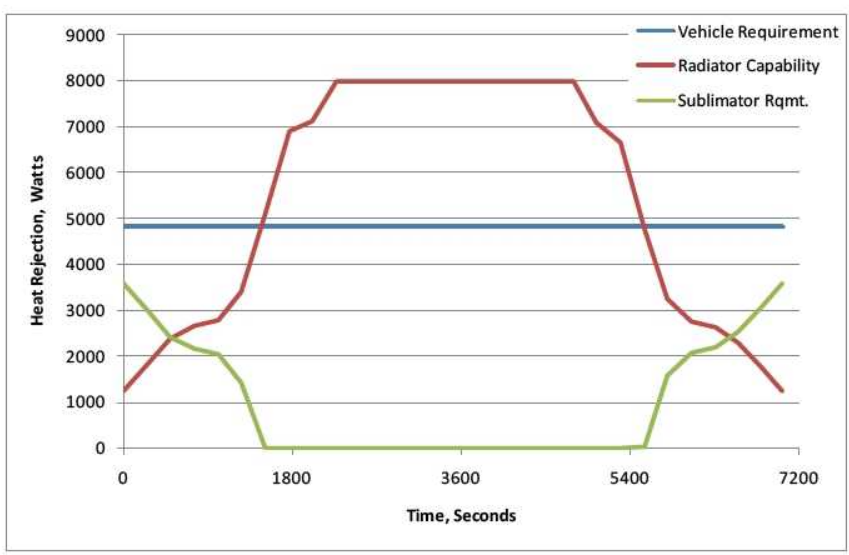

Figure 9. Altair heat rejection requirement (blue), radiator capability (red), and supplemental heat rejection requirement (green) as a function of mission time in low Lunar orbit.

The blue curve in Figure 9 represents the heat rejection requirement for Altair's thermal control system. In this plot, the heat rejection requirement is a time-weighted average of the LLO heat rejection requirement shown in Figure 3. The red curve represents Altair's radiator capability assuming a constant average radiator temperature. The radiator capability is defined as:

$\mathrm{Q}=\varepsilon \sigma \mathrm{A}\left(\mathrm{T}_{\mathrm{R}}^{4}-\mathrm{T}_{\infty}^{4}\right)$

Equation 1

Where:

$$
\begin{aligned}
& Q=\text { Radiator heat rejection (Watts) } \\
& \varepsilon=\text { Infrared emissivity (Dimensionless) } \\
& \sigma=\text { Stefan-Boltzmann constant }\left(\mathrm{W} / \mathrm{m}^{2}-\mathrm{K}^{4}\right) \\
& \mathrm{A}=\text { Radiator surface area }\left(\mathrm{m}^{2}\right) \\
& \mathrm{T}_{\mathrm{R}}=\text { Average radiator temperature (Kelvin) } \\
& \mathrm{T}_{\infty}=\text { Radiator sink temperature (Kelvin) }
\end{aligned}
$$

This figure clearly shows that the radiator capability varies throughout the Lunar orbit. This variability can be explained by studying Figure 8 . It is apparent that the IR backload incident upon Altair will change throughout the orbit due to the changing Lunar surface temperature. In addition, the incident solar load will also vary throughout the orbit. The combination of these effects leads to a wide sink temperature variation in LLO. As depicted in Equation 1 , the heat rejection capability of the proposed Altair radiator will vary as the sink temperature changes.

Altair's thermal control system must be capable of rejecting the full vehicle heat load (approximately $4.8 \mathrm{~kW}$ in this example) throughout the entire orbit. Therefore, the supplemental heat rejection device must dissipate the difference between the heat rejection requirement and the radiator capability, which is shown by the green curve in Figure 9.
The selection of the proper SHReD depends on the duration of the LLO mission phase. For short mission durations such as Altair, an evaporative heat sink would be used as the supplemental heat rejection device. A phase change material heat exchanger would likely be selected for longer mission durations. As described above, Altair requires a sublimator during both Lunar ascent and descent. Therefore, the same sublimator has been chosen as the SHReD during LLO. A sublimator has never before been used in this fashion. A trade study was recently completed and uncovered two potential problems with using a sublimator as a supplemental heat rejection device. Current sublimators have a minimum heat load requirement which would result in a poor orbit-averaged feedwater efficiency (or utilization). In addition, there is concern that the hardware may burst during periods when the sink temperature is relatively cold and the heat load on the sublimator is quite low or possibly non-existent.

The technology development project has developed a plan to mitigate this risk. A sublimator coupon has been fabricated and several operational modes were assessed to quantify the aforementioned Orbit-Averaged Feedwater Utilization (OAFU). The sublimator coupon was used to reduce the concern associated with rupturing the hardware. Now that these tests reduced this concern, the project will use an existing, flight sublimator to assess the OAFU for the current state of the art. If warranted, a design, analysis, and fabrication process will be completed to develop a suitable transient sublimator. Of course, Altair is interested in the results of this study. Orion is also interested in the results as they may consider using a sublimator in a similar fashion.

RADIATORS - Radiator advancement is perhaps the most critical technology development for all of the upcoming Lunar missions. NASA has no history of using radiators to reject the excess heat from a habitable vehicle on the Lunar surface. The Lunar Excursion Module (Apollo version of the Lunar lander) relied on an evaporator, specifically a sublimator, during its relatively short surface stay and the Lunar rovers only used a radiator to refreeze the Phase Change Material (PCM) heat exchangers. However, because of Altair's longer surface stay requirement of seven days (LEM was only three days) the use of an evaporator is not mass efficient for the heat rejection requirements.

One of the most significant design challenges encountered when developing a radiator, which was briefly mentioned above, is liquid freezing within the coolant lines attached to the radiator surface. Typically radiators remove the energy from the coolant lines flowing through the radiator and reject that energy to space. Radiator surface area is one of the key factors contributing to the rate at which energy is rejected to space. The Altair radiators are sized for the maximum heat load in the warmest continuous thermal environment, which happens to be Lunar surface operations. In order to dissipate a high heat load in a relatively warm environment, it is necessary to design radiator with a large surface area. However, when that same radiator is required 
to dissipate a much lower heat load in a cold environment, the surface temperature dramatically decreases. This decreased surface temperature can lead to fluid freeze within the radiator coolant lines if the radiator is not correctly designed. The resultant frozen fluid can be problematic. The radiator must be designed to dissipate a high heat load during Lunar surface operations, but must also be capable of operations at very low heat loads during the translunar coast. Translunar coast is an extremely cold environment because the Altair radiators will be shadowed from the sun during the entire mission phase. The requirement to operate at both a high load and low load is referred to as the system turndown ratio $\left(\mathrm{Q}_{\max } / \mathrm{Q}_{\min }\right)$. The Altair turndown ratio as shown in Figure 3, is approximately six to one.

The high turndown ratio requirement resulted in a two-loop thermal control system architecture. A two-loop architecture is advantageous because the external loop can include a fluid with a very low freezing temperature. Unfortunately, fluids with low freezing points (Freon ${ }^{\circledR}$, ammonia, etc...) are typically toxic and cannot be located inside the pressurized volume due to crew safety concerns. The biggest drawback to a dual-loop system is the increased mass associated with both loops. The addition of a second loop requires several additional hardware components and a slight increase in the required radiator area due to inefficiencies associated with the inter-loop heat exchanger. Orion originally baselined a single loop system, but recently switched to a two-loop system due to the aforementioned issues. The addition of the second loop increased the thermal control system mass by approximately $18 \%{ }^{4}$. The technology development project is seeking to overcome this extremely difficult design challenge. The project is pursuing the development of three separate variable heat rejection radiator technologies. These technologies include variable emissivity electrochromics, a digital radiator ${ }^{5}$, and a freezable radiator design. Coupons either have been or will be fabricated and tested for the three concepts. The project is currently in the process of designing three Altair radiator systems using the three aforementioned technologies. The three radiator concepts will be compared for thermal performance, mass, power, reliability, and technology readiness level. The most promising of these technologies will be included in an integrated thermal vacuum test.

\section{CONCLUSION}

NASA is currently in the process of designing the next generation Lunar lander, Altair. The vehicle must successfully operate through a wide range of mission profiles including operations in Low Earth Orbit, TransLunar Coast, Low Lunar Orbit, and on the Lunar surface. Each of these mission segments present a unique and challenging thermal environment. The Altair project has completed a baseline design for the thermal control system. This design successfully accomplishes the three basic functions required of a thermal control system.
NASA is also in the process of developing advanced technologies to mitigate key thermal risks for Altair and to develop low mass alternatives to the current thermal control system design. These pursuits include thermal control system fluids, advanced heat exchanger designs, evaporator technologies, and variable heat rejection radiators. Ideally, these technologies will be included in future Altair thermal control system designs.

\section{ACKNOWLEDGEMENTS}

The author of this paper is the Altair thermal system manager and the project manager for the technology development project. The author would like to thank his division management and Altair project office personnel for giving him the opportunity to work on the next generation Lunar lander. He would also like to thank all of the individuals involved with making the technology development project a successful project. The project members are from a variety of NASA field centers including GRC, GSFC, JPL, and JSC. In addition to this dedicated workforce, the project also collaborates with various industry partners including Pacific Northwest National Laboratories, Energy Science Laboratories, Paragon Space Development, Jacobs Engineering, Oceaneering Space Systems, Hamilton Sundstrand, and Ashwin-Ushas Corporation.

\section{REFERENCES}

1. Polsgrove, T., Button, R., Linne, D. "Altair Lunar Lander Consumables Management." AIAA SPACE 2009 Conference \& Exposition. September 2009.

2. Sheth, R., Stephan, R. A., Leimkuehler, T. O., "Testing and Model Correlation of Sublimator Driven Coldplate Coupons.” SAE ICES Paper 09ICES-0303. July 2009.

3. Leimkuehler, T. O., Sheth, R., Stephan, R. A., "Investigation of Transient Sublimator Performance." SAE ICES Paper 09ICES-0284. July 2009.

4. Ochoa, D. A., Ewert, M., "A Comparison Between One- and Two-Loop ATCS Architectures Proposed for CEV." SAE ICES Paper 09ICES-0353. July 2009.

5. Ganapathi, G., Sunada, E. T., Birur, G., Miller, J., Stephan, R. A "Design Description and Initial Characterization Testing of an Active Heat Rejection Radiator with Digital Turn-Down Capability." SAE ICES Paper 09ICES-0306. July 2009. 